Килъдюшов О.В. Итальянский традиционалист в контексте немецких консерваторов : рецензия на новую книгу Амитрия Моисеева // Философия. Журнал Высшей школы экономики. - 2021. - Т. 5, № 2. - С. 273-283.

\title{
Олег КИльдЮшов*
}

\section{ИТАЛЬЯНСКИЙ ТРААИЦИОНАЛИСТ В КОНТЕКСТЕ НЕМЕЦКИХ КОНСЕРВАТОРОВ**}

\author{
РЕЦЕНЗИЯ НА НОВУЮ КНИГУ АМИТРИЯ МОИСЕЕВА
}

\author{
МОИСЕЕВ А. С. ПОЛИТИЧЕСКАЯ АОКТРИНА ЮЛИУСА ЭВОЛЫ В КОНТЕКСТЕ \\ «КОНСЕРВАТИВНОЙ РЕВОЛЮЦИИ》 В ГЕРМАНИИ. - ЕКАТЕРИНБУРГ : КАБИНЕТНЫЙ \\ УЧЕНЫЙ, 2021. \\ DOI: $10.17323 / 2587-8719-2021-2-273-283$.
}

Автор рецензируемой здесь работы уже известен научной общественности благодаря вышедшему всего два года назад исследованию политикофилософских импликаций итальянского фашизма (Моисеев, 2019). Несмотря на столь специфический предмет, та книга была с интересом встречена отечественной читающей публикой. Это отразилось в ряде амбивалентных откликов, в том числе в данном издании (Тесля, 2018) ${ }^{1}$.

Новый труд исследователя также посвящен европейской правой политической мысли первой половины 20-х, однако на этот раз Дмитрий Моисеев не ограничивается одной лишь реконструкцией взглядов конкретных мыслителей, а пытается осуществить содержательное сравнение воззрений таких довольно гетерогенных авторов, как итальянский традиционалист Юлиус Эвола, с одной стороны, и видные немецкие «консервативные революционеры»-с другой. Данное сочинение генетически является расширенной и дополненной версией магистерской

*Кильдюшов Олег Васильевич, научный сотрудник; Центр фундаментальной социологии НИУ ВШЭ (Москва), okildyushov@hse.ru, ORCID: о0оo-0001-9801-1952.

** (C) Кильдюшов, О.В. (C) Философия. Журнал Высшей школы экономики.

Благодарности: публикация подготовлена в рамках исследовательского проекта Центра фундаментальной социологии НИУ ВШЭ «Этика солидарности и биополитика карантина: теоретические проблемы культурно-политических трансформаций в эпоху пандемий», реализуемого в рамках Программы фундаментальных исследований НИУ ВШЭ в 2021 г.

${ }^{1}$ См. общий критический вывод рецензента: «...заголовок которой, увы, обещает гораздо больше, чем дает содержание» (Тесля, 2018: 218). 
диссертации автора ${ }^{2}$. C помощью такого сопоставления идей знаменитого барона-эзотерика со взглядами Освальда Шпенглера, Артура Меллера ван ден Брука и Эрнста Юнгера он надеется дать содержательно обоснованный ответ на вопрос о структурных характеристиках правого дискурса в межвоенной Европе. В первую очередь его интересует здесь отношение всех названных авторов к базовым проблемам эпохи: начиная с онтологии и заканчивая их взглядами на хозяйственное устройство, культуру, массовое общество, а также определение «образа врага». Своей первичной целью Д. Моисеев ставит анализ конкретных положений политических теорий данных мыслителей «в контексте наиболее значимых обстоятельств их жизни и эпохи». Именно их «сущностную однородность» исследователь обещает сравнить, что должно позволить отнести доктрины Эволы и немецких «консервативных революционеров» к правому сегменту идеологического спектра (Моисеев, 2021: 26).

При этом чуть выше, обосновывая свой выбор для дальнейшего сопоставления этих фигур, а не других видных представителей «консервативно-революционного» направления - например, Карла Шмитта, Эдгара Юлиуса Юнга, Ханса Фраера и др.,-- Моисеев как бы «априорно» считает, что отобранные им мыслители «имеют достаточно много явных пересечений с положениями политической доктрины Ю. Эволы», что, на его взгляд, собственно, и «позволяет провести ясный сравнительный анализ» (там же: 20)3․

Здесь имеет смысл немного остановиться и сделать ряд замечаний структурного свойства о самом жанре компаративистики в области интеллектуальной истории. K сожалению, у нас и не только давно утвердилась сомнительная практика эвристически немотивированных сравнений различных деятелей, оставивших заметный след в развитии духа. Сравнений, которые ничего не прибавляют к нашему пониманию как самих этих фигур, так и общей дискурсивной ситуации в тот или иной временной момент культурной истории. При этом регулярно по различным параметрам сравнивают как идеи русских мыслителей с западными современниками, предшественниками и последователями, так и европейских между собой - достаточно посмотреть темы защищаемых

${ }^{2} \mathrm{~B}$ обзоре русскоязычной литературы по теме диссертация названа единственной академической работой об Эволе на русском языке (Моисеев, 2021: 42).

3 Еще один аргумент автора в пользу выбора конкретно Шпенглера и Эрнста Юнгера«положительное отношение самого Эволы» к ним (там же: 20). 
диссертаций по истории философии. Как подметил Кристоф Шарль, автор ставшего уже классическим сравнительного исследования европейских интеллектуалов, часто результат такого рода «компаративных исследований» известен заранее и редко выходит за рамки перечисления очевидных совпадений / различий у представителей разных интеллектуальных культур и течений. Ведь и так понятно, что уже в силу страновых смещений в истории европейского модерна сравниваемые концепты и тексты даже у носителей формально схожих политических взглядов могут семантически сильно отличаться. Необходимо ясное понимание прагматики любого транскультурного сопоставления, чтобы сравнение действительно стало эвристическим средством для выработки объяснительных гипотез, а не способом подтверждения очевидных тавтологий по принципу: для французских интеллектуалов характерны определенные признаки, поскольку они являются французами, т. е. обусловлены особенностями французской истории и культуры (Charle, 1996). Стоит ли говорить, что эвристическая прибавочная стоимость такого рода сравнений стремится к нулю и лишь дискредитирует давно проверенный метод исторической компаративистики в сфере истории идей...

Судя по всему, автор рецензируемой книги тоже видит опасность получить в качестве результата предпринятого им исследования интуитивно ожидаемый каталог семантических, жанрово-стилевых и даже интонационных различий и совпадений в корпусе текстов Ю. Эволы и О. Шпенглера, А. Меллера ван ден Брука и Э. Юнгера. В любом случае он пытается максимально точно реконструировать взгляды итальянского традиционалиста и его немецких визави, чтобы затем выявить общее смысловое поле правой политической мысли межвоенной Европы ${ }^{4}$ с целью определения рамочных проблем эпохи, пусть и в сильно отличающихся формулировках. Методически это может быть оправданно, поскольку именно на решение этих структурных дилемм были направлены теоретические и эмоциональные усилия правых интеллектуалов стран догоняющей модернизации, каковой являлась не только Италия, но и Германия (по крайней мере, политически). Тем более что, несмотря на известную гетерогенность идейно-идеологических традиций, персонифицируемых итальянским и немецкими мыслителями, интеллектуалы,

4 Пьер Бурдье язвительно называет это отчетливо выделяющееся семантическое пространство правых идеологий и мировоззрений 1920-1930-х годов «метафизикополитической вульгатой». См.: Бурдье, Бикбов и Анисимова, 1996: 26. 
как функционально уникальная социальная группа, оперирующая универсально значимыми смыслами, определяют свое место не только внутри специфической дискурсивной ситуации в собственной стране, но в более широком интернациональном контексте идей и людей 5 .

Вероятно, именно сильное желание осуществить как можно более предметное сопоставление в рамках ясно очерченных тематических границ, но внутри разнообразных правых дискурсивных формаций в Европе первой половины 20 века обусловило довольно упрощенную структуру работы. Помимо введения «О политических сигнификациях. Понятие „правового“» (Моисеев, 2021: 11-47), представляющего особый социально-теоретический интерес, книга состоит всего из двух объемных глав, скорее напоминающих части или разделы: первая глава носит говорящее название «Политическая доктрина Юлиуса Эволы. Восстание духа» (там же: 48-193), а во второй обсуждается тема «Консервативная революция» в Германии. Философские и политические истоки движения. Творчество Освальда Шпенглера, Артура Меллера ван ден Брука и Эрнста Юнгера (там же: 194-291). Само это неконвенциональное по объему название главы указывает на не слишком продуманный дизайн работы: очевидно, что более логично было бы посвятить отдельные главы всем ключевым героям повествования.

Но самое поразительное в структуре книги даже не это неудачное структурирование материала, а отсутствие полноценного раздела, где бы автор осуществил обещанное сравнение ключевых идей Эволы со взглядами немецких «консервативных революционеров»! По совершенно непонятным причинам сопоставление их воззрений дается в довольно небольшом по размеру заключении, название которого носит несколько тавтологический характер:

Юлиус Эвола - «консервативный революционер»? Сходства и различия во взглядах Эволы и представителей «консервативной революции» в Германии (там же: 292-303).

Таким образом, содержание книги по большей части не соответствует заявленному в названии исследовательскому замыслу. Вместо обещанного сравнительного исследования читатель обнаруживает слабо связан-

$5 Э$ то верно в том числе применительно к авторам правых нарративов, часто позиционирующих себя путем прямого противопоставления идейно-политическим влияниям извне (например, со стороны лидеров модерна в лице ведущих западных стран), но на практике вынужденных так или иначе содержательно реагировать на них - пусть даже путем радикальной критики или стигматизации. 
ные между собой очерки в духе интеллектуальной биографии четырех персонажей европейской истории политической мысли. Видимо, тематическую целостность всему тексту должна придать обрамляющая две главы эвристическая рамка, содержащаяся во введении и заключении.

В этой ситуации наиболее значимым разделом книги с точки зрения социально-теоретической проблематизации правых интеллектуальных проектов в контексте катастрофического опыта европейского модерна 20 века является именно введение, в котором Д. Моисеев формулирует свою амбициозную исследовательскую программу, во многом оставшуюся нереализованной из-за основного акцента на подробную реконструкцию представлений названных мыслителей. Автор начинает вводную часть с крайне содержательных размышлений о смысле противопоставления левое- - равое в истории идей и политической практике модерна. Для демонстрации сохраняющейся содержательной значимости этих понятий он выбирает ряд фундаментальных оппозиций: отношение носителей левых и правых мировоззрений/идеологий к онтологии, равенству, истории, социальной стратификации и примату политического или экономического (Моисеев, 2021: 14-16). Их также можно распространить на вопросы культуры, социальной политики и т. д. При этом исследователь выдвигает сразу несколько спорных тезисов, доказательство которых могло бы стать предметом отдельной работы. Прежде всего это касается несколько умозрительного утверждения об идеалистическом характере всякой правой онтологии, якобы неизбежно принимающей форму религии или философской спекуляции. Как известно, спецификой мировоззрения любого консерватора является именно то, что он максимально всерьез принимает существующее положение вещейбуквально в его материальной форме, - получающее соответствующую легитимацию в культурной традиции. Напротив, вооруженные теорией прогресса левые крайне легко расстаются со сложившимися формами материального мира. Это же касается мнимого приоритета экономики над политикой у левых: как показывает реальная политическая практика модерна, все левацкие режимы готовы по чисто доктринальным соображениям осуществлять самые безумные социальные эксперименты, полностью игнорируя в своей политике экономические мотивы и т. д.

Не менее проблематичными являются некоторые утверждения автора, содержащиеся в ключевом параграфе введения «Предмет исследования и постановка цели». Например, межвоенная Европа неудачно сравнивается с «плавильным котлом» для различных партий и мировоззрений. 
Помимо того, что данная семантика традиционно относится к (само)описанию Америки на определенных этапах ее культурно-идентитарной истории, Старый континент скорее являлся тогда своеобразной лабораторией по выработке всевозможных дискурсивных формаций. Еще одним странным с точки зрения социологии знания тезисом является фактическое отождествление интеллектуала как нового социального типа модерна с фигурой политического публициста вроде обсуждаемых в книге правых мыслителей:

Интеллектуал- фигура более свободная, чем политик и ученый; не имя формальных ограничений, он мог творить так, как считал нужным-насколько позволяли ему рамки избранного им дискурса (Моисеев, 2021: 18).

Стоит ли говорить, что более конвенциональным является восходящее к Максу Веберу представление об интеллектуалах как о специалистах по обращению с символическими ресурсами, задающих в рамках определенной культуры смысловые вехи, на которые впоследствии ориентируется социальное действие в ходе практической реализации акторами их «собственных» интересов. В этом смысле интеллектуал может быть как ученым, так и политиком - здесь достаточно вспомнить широкий дискурсивный репертуар самого Вебера, с разным успехом пытавшегося выступать в разных интеллектуальных жанрах...

Также эвристически значим параграф «Актуальность цели. К вопросу о разграничениях и связях» (там же: 22-26), в котором автор выделяет несколько аспектов возможного отнесения творчества Юлиуса Эволы к числу работ мыслителей «консервативной революции». Первый политически важный момент связан с общей дискредитацией правой идеи после Второй мировой войны. Д. Моисеев справедливо указывает на тень нацизма, накрывшую консерваторов, реакционеров и традиционалистов всех мастей как симпатизантов тоталитарных режимов 20 века. Мало того что такое отождествление часто оригинальных идей правых теоретиков с одиозными практиками фашизма и национал-социализма просто необоснованно с точки зрения фактической интеллектуальной истории, оно к тому же маргинализирует огромный пласт духовной культуры Европы, в том числе препятствуя добросовестному его изучению средствами науки. Второй аспект вытекает из запутанной интеллектуальной биографии Ю. Эволы, предстающего для разных групп интересантов в разных лицах: от деятеля авангарда до борца с современностью, от автора научных работ по буддизму до практикующего оккультиста. Наконец, третий аспект авторской постановки проблемы 
заключается в необходимости аналитической разметки внутри самой правой политической мысли. В качестве примера «интегрирующего подхода», смело записывающего итальянского барона и немецких консерваторов в стан современных борцов с атлантизмом, исследователь приводит А. Г. Дугина (Моисеев, 2021: 24-25). Здесь Моисеев открыто отстаивает приоритет интеллектуальной честности перед возможными выгодами политической инструментализации.

Для всех интересующихся проблематикой правой мысли представляет интерес и обзор основной литературы по теме, данный в параграфе «Состояние рассматриваемого вопроса» (там же: 26-42). Автор начинает его с классической работы Армина Молера 1951 года (Молер, Васильченко, 2017) и затем переходит к более современным публикациям, посвященным героям книги. Здесь же приводятся русскоязычные переводы трудов Юнгера, Шмитта, Шпенглера и др. Завершает параграф критический разбор важнейших работ отечественных исследователей «немецкой консервативной революции».

Стоит отдельно обсудить методологические подходы и методические приемы, которые Д. Моисеев называет основными для своего исследования. Как и в предшествующей книге, посвященной политической философии итальянского фашизма, автор декларирует свою приверженность четырем герменевтическим принципам историко-философской реконструкции, сформулированным Эмилио Бетти: герменевтическая автономия изучаемого объекта, тотальность и смысловая связанность, актуализация чужого опыта, синхронизация мысли интерпретатора с исходными интенциями оригинала (Бетти, Борисов, 2011). При этом интеллектуальная история рассматривается исследователем не в качестве жанра или дисциплины социального знания, а именно как особый метод. Его отличие, например, от историко-философского подхода он видит в необходимости помимо содержания самой идеи также учитывать максимально широкий контекст институциональных изменений, социальной борьбы, интеллектуальной биографии и т. д. Также автор эксплицитно обращается к эвристическим ресурсам социологии, в том числе социологии знания, причем в несколько архаичном по меркам современного социального знания маннгеймовском духе. Стоит ли говорить, что объяснение контента через социальную позицию автора выглядит как социологический редукционизм, излишне упрощающий картину «социальной взаимообусловленности» интеллектуала и его общественного положения... 
В этом смысле бросается в глаза отсутствие в работе когнитивной рамки в виде общей проблематики европейского модерна, уже неизбежной при реконструкции таких дискурсивных артефактов эпохи, как реакции правых интеллектуалов на модернизационные вызовы и катастрофы 20 века. Между тем рамочная топика в духе макро- или исторической социологии модерна может открыть нормативную теоретическую перспективу, позволяющую критически тематизировать идейно-идеологические продукты, связанные с творчеством названных мыслителей, не прибегая к несколько избыточной защите политически токсичного предмета исследования от «клеветы профана».

Отдельно следует отметить явные усилия Д. Моиссева по эстетической самостилизации в духе жестов и текстов рассматриваемых в книге авторов. Помимо места и даты написания предисловия, самым заметным элементом подобного автосоотнесения автора к кругу правых интеллектуалов является перегруженность сочинения цитатами из древних и новых. Например, введение открывается сразу двумя эпиграфами, позаимствованными у римских императоров Марка Аврелия и Юлиана Отступника. Подобные обращения понятны не только стилистически, но и эвристически. Здесь можно вспомнить рассуждение Ханса Фраера о Макиавелли, также обращавшегося к древнеримским образцам (Фрайер, Кузницын, 2011: 136-137):

Обращение к античности становится важным средством для переосмысления эмпирического в действительное, единичного во всеобщее. [...] Античность содержит неисчерпаемый запас нормативных образов, и, опосредуя ими свой собственный опыт, мы очищаем его до уже более чем наших личных познаний.

Однако современный отечественный исследователь не ограничивается мудростью Древнего Рима и обрушивает на читателя десятки цитат из мыслителей соответствующей политической, философской и эстетической ориентации (Ницше, Хайдеггера, Генона, Мисимы и т. д.). Эпиграфы подобраны не только к основным разделам книги, но и почти ко всем из 26 глав! Также среди референтных для исследователя авторитетов оказываются писатели, относящиеся к иным интеллектуальным традициям: Лао-Цзы, Мережковский и др. Кажется, нет эпиграфа только к параграфам о политических взглядах Эволы, Шпенглера, Меллера и Юнгера ( $\S 1.13,2.7,2.9,2.13)$, что представляет собой некую загадку для рецензента: автор просто забыл подобрать к ним что-то подходящее? Или сознательно оставил чисто политические разделы 
без программных цитат? В любом случае это абсолютно рекордное число эпиграфов, которое мне когда-либо доводилось видеть в отдельно взятой научно релевантной книге!

Возвращаясь к исходному исследовательскому вопросу об осмысленности соотнесения традиционалиста Юлиуса Эволы с движением «консервативных революционеров» в Германии, следует отметить удачный способ ответа, избранный Д. Моисеевым: прежде чем сделать тот или иной общий вывод, он предлагает читателю сопоставить позиции итальянского барона и немецких консерваторов по конкретным базовым вопросам: образу врага, экономическому укладу, отношению к марксизму, социализму и национализму, а также их взглядам на массовое общество, культуру и технику. В результате он приходит к вполне ожидаемому выводу о том, что, несмотря на значительные совпадения взглядов барона и немецких мыслителей в негативной части его политико-интеллектуальной программы, в позитивной части они различаются настолько значительно, что многие представления Эволы в сравнении с другими героями книги оказываются не столько консервативными, сколько реакционными. Более того, автор приходит к парадоксальному на первый взгляд выводу: утопически обращенный в полумифическое «прошлое» эстетствующий традиционалист Эвола«гораздо больший революционер и гораздо меньший консерватор, чем Шпенглер, Меллер и Юнгер», которые оказываются на его фоне носителями все той же модернизационной парадигмы (Моисеев, 2021: 301).

Пафос послесловия (там же: $304^{-} 307$ ), в котором Дмитрий Моисеев кратко обозревает «руины правой идеи», заключается в созвучной идеям Ю. Эволы элитаристской формуле: только «наилучшее меньшинство» может обнаружить для себя традицию как актуальную в вечности, передать тем самым послание следующим поколениям и сохранить себя для будущего. Можно быть уверенным, что его книга станет обязательным чтением для многих представителей правого фланга русского дискурсивного пространства, остро нуждающегося в современной качественной литературе такого рода для более успешной ориентации в идейно-политических бурях 21 века.

\section{ЛИTEРATУРA}

Бетти Э. Герменевтика как общая методология наук о духе / пер. с нем. Е. В. Борисова. - М. : Канон+, 2011. 
Бурдъе П. Политическая онтология Мартина Хайдеггера / пер. с фр. А.Т. Бикбова, Т.В. Анисимовой. - М : Праксис, 1996.

Моисеев Д. С. Политическая философия итальянского фашизма. Становление и развитие доктрины. - М., Екатеринбург : Кабинетный ученый, 2019.

Моисеев Д. С. Политическая доктрина Юлиуса Эволы в контексте «консервативной революции» в Германии. - Екатеринбург : Кабинетный ученый, 2021.

Молер А. Консервативная революция в Германии 1918-1932/ пер. с нем. А. В. Васильченко. - М. : Тотенбург, 2017.

Tесля A. A. До и вокруг Джованни Джентиле : Об опыте по истории политической философии итальянского фашизма // History of Political Thought. 2018. - T. 20, № 3. - C. 456-493.

Фрайер X. Макьявелли / пер. с нем. Д. В. Кузницына. - М. : Владимир Даль, 2011.

Charle C. Les Intellectuels en Europe au XIXe siècle, essai d'histoire comparée. Paris : Seuil, 1996.

Kil'dyushov, O. V. 2021. "Ital'yanskiy traditsionalist v kontekste nemetskikh konservatorov [An Italian Traditionalist in the German Conservative Context]: retsenziya na novuyu knigu Dmitriya Moiseyeva [A Review of Dmitry Moiseev's New Book]" [in Russian]. Filosofiya. Zhurnal Vysshey shkoly ekonomiki [Philosophy. Journal of the Higher School of Economics] 5 (2), 273-283.

\author{
OLEG Kil'DYUSHOV \\ RESEARCH FELLOW \\ Centre for Fundamental Sociology \\ National Research University - Higher School of Economics (Moscow, Russia); \\ ORCID: 0000-0001-9801-1952
}

\title{
An Italian Traditionalist in the German Conservative Context
}

\section{A Review of Dmitry Moiseev's New Book}

Moiseyev, D. S. 2021. Politicheskaya doktrina Yuliusa EVOly V KonteKste "Konservativnoy ReVolyutsit" V Germanil [The Political Doctrine of Julius Evola in the Context of the "Conservative ReVolution" in Germany] [in Russian].

YEKATERINBURG: KABINETNYY UCHENYY

DOI: $10.17323 / 2587-8719-2021-2-273-283$.

\section{REFERENCES}

Betti, E. 2011. Germenevtika kak obshchaya metodologiya nauk o dukhe [in Russian]. Trans. from the German by Ye. V. Borisov. Moskva [Moscow]: Kanon+. 
Bourdieu, P. 1996. Politicheskaya ontologiya Martina Khaydeggera [L'Ontologie politique de Martin Heidegger] [in Russian]. Trans. from the French by A. T. Bikbov and T.V. Anisimova. M: Praksis.

Charle, Ch. 1996. Les Intellectuels en Europe au XIXe siècle, essai d'histoire comparée [in French]. Paris: Seuil.

Freyer, H. 2011. Mak'yavelli [Machiavelli] [in Russian]. Trans. from the German by D. V. Kuznitsyn. Moskva [Moscow]: Vladimir Dal'.

Mohler, A. 2017. Konservativnaya revolyutsiya v Germanii 1918-1932 [Die Konservative Revolution in Deutschland 1918-1932] [in Russian]. Trans. from the German by A. V. Vasil'chenko. Moskva [Moscow]: Totenburg.

Moiseyev, D.S. 2019. Politicheskaya filosofiya ital'yanskogo fashizma. Stanovleniye $i$ razvitiye doktriny [Political Philosophy of the Italian Fascism. Evolution and Formation of the Doctrine] [in Russian]. Moskva [Moscow] and Yekaterinburg: Kabinetnyy uchenyy.

- 2021. Politicheskaya doktrina Yuliusa Evoly v kontekste "konservativnoy revolyutsii" v Germanii [The Political Doctrine of Julius Evola in the Context of the "Conservative Revolution" in Germany] [in Russian]. Yekaterinburg: Kabinetnyy uchenyy.

Teslya, A. A. 2018. "Do i vokrug Dzhovanni Dzhentile [Before and around Giovanni Gentile]: $\mathrm{Ob}$ opyte po istorii politicheskoy filosofii ital'yanskogo fashizma [About the Experience on the History of the Political Philosophy of Italian Fascism]" [in Russian]. History of Political Thought 20 (3): 456-493. 